\title{
Clozapine Acts as an Agonist at Serotonin 2A Receptors to Counter MK-80I-Induced Behaviors through a $\beta$ Arrestin2-Independent Activation of Akt
}

\author{
Cullen L Schmid', John M Streicher ${ }^{1,3}$, Herbert Y Meltzer² and Laura M Bohn*,' \\ 'Department of Molecular Therapeutics and Neuroscience, Scripps Research Institute, Jupiter, FL, USA; ${ }^{2}$ Department of Psychiatry and \\ Behavioral Sciences and Physiology, Northwestern University Feinberg School of Medicine, Chicago, IL, USA
}

\begin{abstract}
The G protein-coupled serotonin 2A receptor (5-HT2AR) is a prominent target for atypical antipsychotic drugs, such as clozapine. Although clozapine is known to inhibit 5-HT2AR signaling through G protein-dependent mechanisms, it differs from classic GPCR antagonists, in that it also induces 5-HT2AR internalization and activates Akt signaling via a 5-HT2AR-mediated event. In this regard, clozapine may also be considered a functionally selective agonist. The cognate neurotransmitter at the 5-HT2AR, serotonin, also induces 5-HT2AR internalization and Akt phosphorylation. Serotonin promotes interactions with the scaffolding and regulatory protein, $\beta$ arrestin2, which results in the recruitment and activation of Akt. These interactions prove to be critical for serotonin-induced, 5-HT2AR-mediated behavioral responses in mice. Herein, we sought to determine whether clozapine also utilizes $\beta$ arrestin2-mediated mechanisms to induce 5-HT2AR signaling, and whether this interaction contributes to its behavioral effects in mice. We demonstrate that unlike serotonin, clozapine-mediated 5-HT2AR internalization and Akt phosphorylation is independent of receptor interactions with $\beta$ arrestin2. Moreover, clozapine-mediated suppression of MK-80I and phencyclidine (PCP)-induced hyperlocomotion is $\beta$ arrestin2 independent, although it is dependent upon Akt. These results demonstrate that pharmacologically oppositional ligands, serotonin and clozapine, utilize differential mechanisms to achieve the same 5-HT2AR-meadiated downstream events: Akt phosphorylation and receptor internalization. Although $\beta$ arrestin2 has no effect on clozapine's actions in vivo, Akt phosphorylation is required for clozapine's efficacy in blocking MK-80I- and PCP-induced models of schizophrenic behaviors in mice.
\end{abstract}

Neuropsychopharmacology (2014) 39, 1902-1913; doi:I0.1038/npp.2014.38; published online 2 April 2014

\section{INTRODUCTION}

The atypical antipsychotic clozapine is widely considered the 'gold standard' for the treatment of schizophrenia as it is one of the most efficacious antipsychotics on the market (Meltzer, 2012, 2013). Unfortunately, the therapeutic use of clozapine is limited because the drug causes a number of undesirable side effects, including agranulocytosis, sedation, and metabolic side effects such as hyperlipidosis and weight gain. Given that clozapine binds to a wide range of targets, including numerous members of the serotonin, dopamine (DA), histamine, adrenergic, and muscarinic classes of receptors, the mechanisms underlying both the therapeutic and unwanted effects of the drug remain unclear (Meltzer and Huang, 2008; Roth et al, 2004).

* Correspondence: Professor LM Bohn, Department of Molecular Therapeutics, Scripps Research Institute, 130 Scripps Way, \#2A2, Jupiter, FL 33458, USA, Tel: +56I 228 2227, Fax: +56I 228 308I, E-mail: Ibohn@scripps.edu

${ }^{3}$ Current address: Department of Biomedical Sciences, University of New England, Biddeford, ME 04005, USA.

Received I8 November 20 I3; revised 10 February 20 I4; accepted 13 February 2014; accepted article preview online 17 February 2014
Clozapine binds to the $\mathrm{G}$ protein coupled, serotonin 2A receptor (5-HT2AR) with high affinity and there is considerable evidence to suggest that its efficacy for treating the symptoms of schizophrenia, despite weak affinity for DA D2 receptors, is due to its activity at 5-HT2AR in the mesocortical pathways (Meltzer and Massey, 2011). Blockade of NMDA receptors by dizocilpine (MK-801) or phencyclidine (PCP) produces hyperlocomotor activity in rodents; this effect has been extensively studied as a model of psychotic symptoms, specifically hallucinations and delusions (Jones et al, 2011). Clozapine, as well as all other drugs that are effective in treating schizophrenia in human patients, suppress MK-801- or PCP-induced hyperactivity in mice, and this effect has been shown to be due to its actions at 5-HT2AR (Fribourg et al, 2011; Gainetdinov et al, 2001; Gleason and Shannon, 1997; Millan et al, 1999). Recent studies have shown that clozapine's ability to decrease basal locomotor activity is mediated in large part by 5-HT2AR expressed in the prefrontal cortex (McOmish et al, 2012; Williams et al, 2012). Moreover, highly selective, high-affinity 5-HT2AR antagonists mimic the locomotor suppression observed with clozapine (Millan et al, 1999; Williams et al, 2012). 
Clozapine is typically considered a potent inverse agonist at the 5-HT2AR (Weiner et al, 2001); however, this classification is complicated by the findings that chronic administration causes downregulation of this receptor in brain (Matsubara and Meltzer, 1989; Moreno et al, 2013; Peroutka and Snyder, 1980; Yadav et al, 2011) and that it can internalize the 5-HT2AR both in vitro and in vivo (Bhatnagar et al, 2001; Raote et al, 2013; Willins et al, 1998, 1999). In addition to causing 5-HT2AR internalization and downregulation, clozapine has also been shown to promote protein kinase B (Akt) phosphorylation in cultured neuronal cells and the rat prefrontal cortex (Dwyer and Donohoe, 2003; Lu et al, 2004; Sutton and Rushlow, 2011; Xi et al, 2011), thereby demonstrating that clozapine can act like an agonist. Interestingly, in Caenorhabditis elegans, clozapine was shown to activate the transcription factor DAF-16 through an Akt- and $\beta$ arrestin-dependent pathways (Weeks et al, 2011). There is growing evidence that ligands cannot be strictly classified as an agonist or antagonist, but rather they must be considered agonists or antagonists with respect to the biological outcome being measured. Although some ligands appear to act as agonists in all assays, others only selectively engage receptors in particular signaling pathways, a concept referred to as functional selectivity or ligand-directed signaling (Rajagopal et al, 2010; Urban et al, 2007).

Previous studies from our laboratory have demonstrated functional selectivity at 5-HT2AR expressed in the mouse frontal cortex for the cognate neurotransmitter serotonin and the $\mathrm{N}$-methyltryptamines. Serotonin-induced 5-HT2AR internalization is dependent upon $\beta$ arrestin2 in both mouse embryonic fibroblasts (MEFs) and in primary cortical neurons, whereas 2,5-dimethoxy-4-iodoamphetamine, a serotonin $2 \mathrm{~A} / 2 \mathrm{C}$ selective hallucinogen agonist, promotes internalization independent of $\beta$ arrestins (Bohn and Schmid, 2010; Schmid et al, 2008). In addition, serotonin induces Akt phosphorylation in the mouse frontal cortex and in primary cortical neurons, via a $\beta$ arrestin $2 / \mathrm{Src} /$ phosphatidylinositol 3 kinase pathway. Furthermore, the activation of this pathway was shown to be necessary for the serotonin-induced (whether directly by administration of serotonin or indirectly by administration of its metabolic precursor 5-hydroxytryptophan) head twitch response, which is a behavioral model of cortical 5-HT2A/2CR activation in mice (Corne and Pickering, 1967; GonzalezMaeso et al, 2007). In contrast, the $N$-methyltryptamines, although acting at 5-HT2AR, do not induce Akt phosphorylation in the mouse frontal cortex and are able to induce the head twitch response independent of $\beta$ arrestin2 (Schmid and Bohn, 2010).

Given that the actions of serotonin and clozapine at 5-HT2AR promote similar downstream signaling events (Akt activation and receptor internalization) and that these events were shown to be dependent on $\beta$ arrestin2 for serotonin, we asked whether clozapine-mediated 5-HT2AR trafficking and signaling events were also dependent upon $\beta$ arrestin2, and whether clozapine's ability to suppress PCP- and MK-801-induced hyperlocomotion was altered in mice lacking $\beta$ arrestin2 ( $\beta$ arr2-KO). We find that clozapine and serotonin stimulate 5-HT2AR internalization and Akt phosphorylation via different mechanisms, with clozapineinducing signaling events independent of $\beta$ arrestin2. How- ever, although $\beta$ arrestin 2 is not critical for the antagonism of MK-801- or PCP-induced hyperactivity in mice, the activation of Akt is required for clozapine's efficacy in this model of psychosis.

\section{MATERIALS AND METHODS}

\section{Drugs}

5-HT hydrochloride, L-5-hydroxytryptophan, clozapine, (+)-MK-801 hydrogen maleate, and PCP hydrochloride were purchased from Sigma-Aldrich (St Louis, MO). Akt Inhibitor VIII, isozyme-selective, Akti-1/2 (Akti) was obtained from Calbiochem/EMD Chemical (Billerica, MA). M100907 was generously provided by Dr Kenner Rice (National Institute on Drug Abuse/National Institute on Alcohol Abuse and Alcoholism/National Institutes of Health, Bethesda, MD). Src tyrosine kinase inhibitor 4-amino-5-(4-chlorophenyl)-7-( $t$-butyl)-pyrazolo[3,4- $d]$ pyrimidine (PP2) was obtained from Tocris Bioscience (Ellisville, $\mathrm{MO})$. Specific vehicles and concentrations/doses are noted in the figure legends.

\section{AArrestin2 Translocation}

To quantify $\beta$ arrestin2 interactions with the 5-HT2AR, the DiscoveRx PathHunter eXpress $\beta$ arrestin assay in human osteosarcoma U2OS cells expressing the human 5-HT2AR was utilized, according to the manufacturer's protocol (DiscoveRx, Fremont, CA). Cells were plated at a density of 5000 cells per well of a 384-well plate in CP19 plating media (DiscoveRx). Cells were treated with agonist for $90 \mathrm{~min}$, followed by a 60 -min enzyme complementation period. For antagonist experiments, cells were incubated with the antagonist $60 \mathrm{~min}$ before agonist addition. Luminescence values were obtained using a Synergy HT luminometer (BioTek, Winooski, VT).

To visually assess $\beta$ arrestin2 translocation by confocal microscopy, HEK-293 cells (ATCC, Manassas, VA) were transiently transfected with $2 \mu \mathrm{g}$ of mouse $\beta$ arrestin $2 \mathrm{cDNA}$, tagged on the C-terminus with green fluorescent protein ( $\beta$ arr2-GFP; GenBank accession \# BC016642) and $5 \mu \mathrm{g}$ $\mathrm{N}$-terminal hemagglutinin-tagged mouse 5-HT2AR (HA-5HT2AR; GenBank accession \# BC108973) cDNA by using the electroporation Gene Pulser XCell electroporation system (Bio-Rad, Hercules, CA). Sixteen to twenty hours post transfection, cells were serum starved for $2 \mathrm{~h}$ in MEM. To confirm 5-HT2AR expression in the cells imaged, the HA-5-HT2AR was live-cell stained using an anti-HA-488 AlexaFluor antibody (1:100; Life Technologies, Grand Island, NY) for $10 \mathrm{~min}$. Confocal images were obtained using an Olympus Fluoview IX81 confocal microscope (Olympus, Center Valley, PA). All images shown in Figure $1 \mathrm{~b}$ have been uniformly adjusted for contrast and brightness once inserted into Keynote'09 software (Apple).

\section{5-HT2AR Trafficking}

WT and $\beta$ arr1/2-KO MEFs were transiently transfected with $5 \mu \mathrm{g}$ N-terminal hemagglutinin-tagged mouse 5 -HT2AR by electroporation. Sixteen hours post transfection, cells were serum-starved for $2 \mathrm{~h}$ and the receptor was stained with the 
anti-HA-488 AlexaFluor antibody, as described above. Cells were treated with $10 \mu \mathrm{M}$ agonist for $30 \mathrm{~min}$ and then confocal images were obtained. All images shown in Figure 1c have been uniformly adjusted for contrast and brightness once inserted into Keynote'09 software (Apple). Percent internalization was quantified using ImageJ analysis Software (National Institutes of Health). The total density of the internalized receptor was normalized to the total density of the receptors expressed within the cells.

\section{Behavioral Experiments}

$\mathrm{WT}$ and $\beta$ arr2-KO male mice, derived from both heterozygous and homozygous breeding (with $<10 \%$ of each experimental group of animals obtained from homozygous crossing), between 3 and 6 months of age were utilized for these studies. Drugs administered intraperitoneally (i.p.) were prepared in $0.9 \%$ saline at a volume of $10 \mu \mathrm{l} / \mathrm{g}$ body weight; Akti was administered intracerebroventricularly (i.c.v.) in $1 \%$ DMSO in $18 \Omega$ purified, distilled, sterile water, and injected at a volume of $3 \mu \mathrm{l}$, according to the specifications described previously (Schmid and Bohn, 2010). For locomotor activity monitoring, mice were habituated in Plexiglas chambers for $30 \mathrm{~min}$ before drug administration. Locomotor activity was monitored by Versamax Animal Activity Monitor (Accuscan Instruments, Columbus, $\mathrm{OH}$ ) during the habituation period, the $30 \mathrm{~min}$ pretreatment periods and for $60 \mathrm{~min}$ following treatment with either MK-801 or PCP. In all cases, animals were only used once and experiments were performed with the approval of the Institutional Animal Care and Use Committee of the Scripps Research Institute.

\section{Primary Neurons and Western Blotting}

Primary neuronal cultures were generated from frontal cortices isolated from postnatal day 1 mouse neonates obtained from homozygous breeding of WT and $\beta$ arr2-KO mice, as described (Schmid and Bohn, 2010; Schmid et al, 2008). Activation of Akt was determined on the fifth day post-plating. Neurons were serum starved for $1 \mathrm{~h}$ before the $10 \mathrm{~min}$ agonist treatment in serum-free MEM. For some studies, M100907 was added during the last $15 \mathrm{~min}$ of the serum-starvation studies, or PP2 was added to the media during the entire $1 \mathrm{~h}$ serum stave. Lysates were prepared and western blots were performed as described (Schmid and Bohn, 2010). Immunoblots were probed with phosphoAkt (1:1000; Thr308 C31E5E, Cell Signaling Technology, Beverly, MA) or total Akt (1:2000; pan C67E7, Cell Signaling Technology) antibodies and immunofluorescence was detected using the Odyssey Infrared imaging system (LiCOR Biosciences, Lincoln, NE). Western blots are shown of continuous gels that have been cropped. Uniform adjustment of contrast and brightness has been linearly applied to the images to improve visibility once inserted into Keynote'09 software (Apple). Densitometry was quantified using ImageJ analysis software. For each sample, phospho-Akt levels were normalized to their corresponding total-Akt levels and fold stimulation was determined by normalizing to the average vehicle levels within each experiment.

\section{Brain Lysates}

To determine Akti-induced inhibition of clozapine-mediated Akt phosphorylation, adult WT mice were treated with $100 \mathrm{ng}$ of Akti (i.c.v., as described above) for $30 \mathrm{~min}$ before treatment with $1 \mathrm{mg} / \mathrm{kg}$ of clozapine (i.p.). Forty-five minutes following clozapine administration, mice were killed by cervical dislocation and frontal cortex was isolated and frozen in liquid nitrogen. Lysates were prepared as detailed previously (Schmid and Bohn, 2010). Akt phosphorylation levels, presentation of western blots, and densitometric analyses were determined as described above.

\section{Statistical Analysis}

All statistical comparisons were made using GraphPad Prism version 5.03 for Windows (GraphPad Software, San Diego, CA). Concentration-response curves were generated by normalizing to the maximal serotonin stimulation (agonist mode) or to $500 \mathrm{nM}$ serotonin (antagonist mode) and then using three parameter (variable slope) agonist and antagonist non-linear regression curve-fit analysis (non-convergence was $R^{2}<0.6$ ). Two-way analysis of variance was utilized to analyze group differences. Student's unpaired, two-tailed $t$-tests were used to compare biochemical data. All statistics were conducted with a confidence interval of $95 \%$ and $p<0.05$ was considered significant. The number of independent experiments is reported in the figure legends $(n)$.

\section{RESULTS}

Initially, we determined whether clozapine had the capacity to recruit $\beta$ arrestin2 to the 5-HT2AR. We used the DiscoveRx PathHunter $\beta$ arrestin assay in U2OS cells expressing the 5-HT2AR to measure the interaction between the 5 -HT2AR and $\beta$ arrestin 2 by enzyme complementation. Serotonin, used as a positive control, stimulates robust interactions between the 5-HT2AR and $\beta$ arrestin2 $\left(\mathrm{EC}_{50}\right.$ $=61.1 \pm 9.2 \mathrm{nM}$ ). As anticipated, neither clozapine nor the selective 5-HT2AR antagonist M100907 induces interactions between $\beta$ arrestin 2 and the receptor (Figure 1a; data do not converge for either compound). In addition, both clozapine and M100907 act as antagonists in this assay, as they both potently and fully block serotonin-induced $\beta$ arrestin2 interactions with the 5-HT2AR (Figure $1 \mathrm{~b}$; clozapine: $\mathrm{IC}_{50}=$ $124.0 \pm 9.7 \mathrm{nM}, \% \operatorname{Imax}=102.6 \pm 1.4 ; \mathrm{M} 100907: \mathrm{IC}_{50}=6.6 \pm$ $0.6 \mathrm{nM}, \% \operatorname{Imax}=94.9 \pm 0.8$ ). Ligand-stimulated $\beta$ arrestin2 translocation was also assessed in HEK-293 cells by confocal microscopy. In the basal state, $\beta$ arr2-GFP is localized throughout the cytosol of HEK-293 cells. Within 10 min of treatment with serotonin, but not clozapine, $\beta$ arr2-GFP translocates to the plasma membrane, as made evident by the punctae localized at the plasma membrane. Pretreatment with clozapine blocks serotonin-induced $\beta$ arr2-GFP translocation (Figure 1c). These studies indicate that clozapine acts as an antagonist in regard to $\beta$ arrestin2 recruitment.

Although a direct interaction between the receptor and tagged- $\beta$ arrestin 2 could not be observed upon clozapine treatment, $\beta$ arrestin 2 may still serve to facilitate events downstream of the receptor. $\beta$ Arrestin interactions with a GPCR can facilitate receptor internalization. To determine 


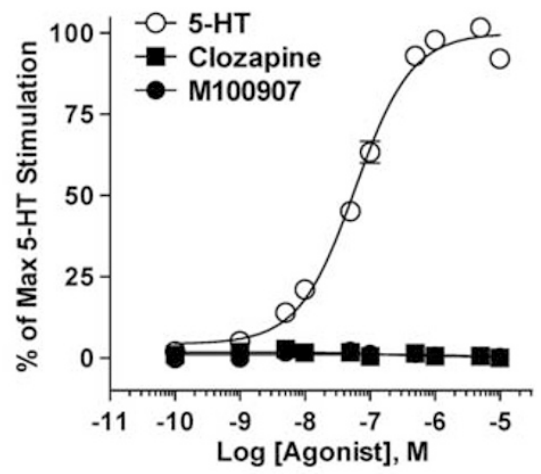

C

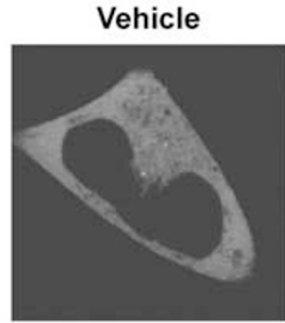

d
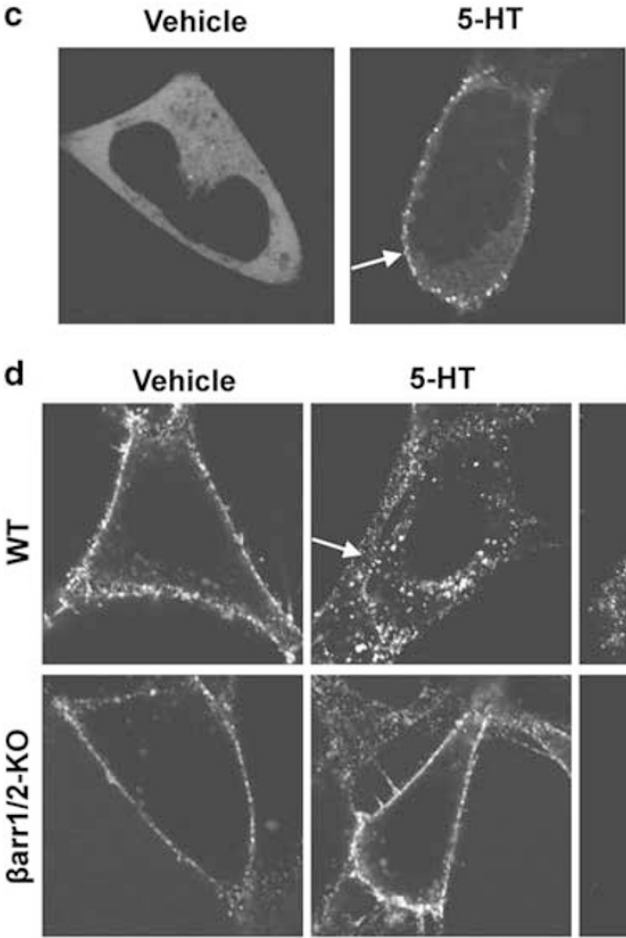

5-HT

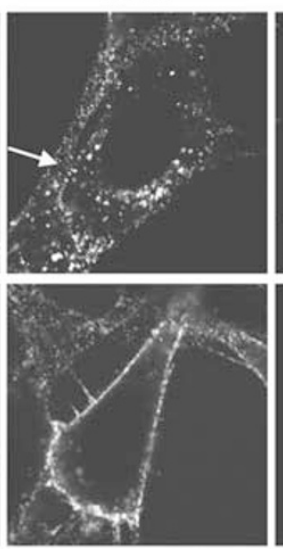

b

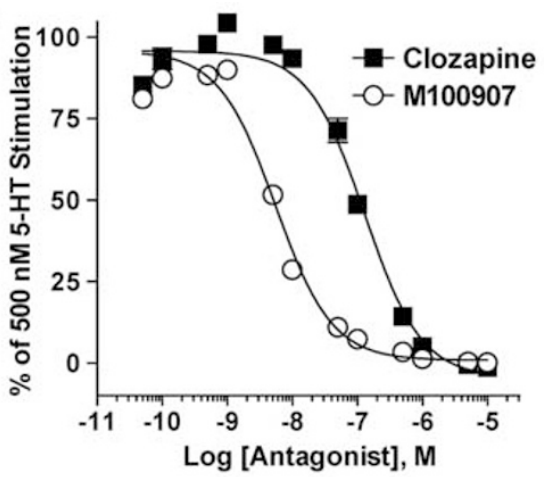

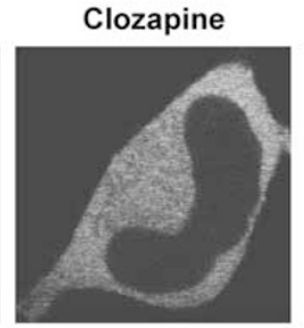

Clozapine + 5-HT

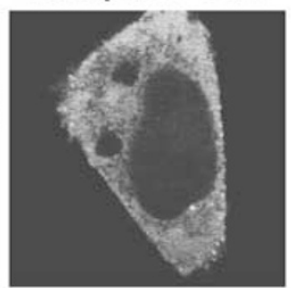

Clozapine

e
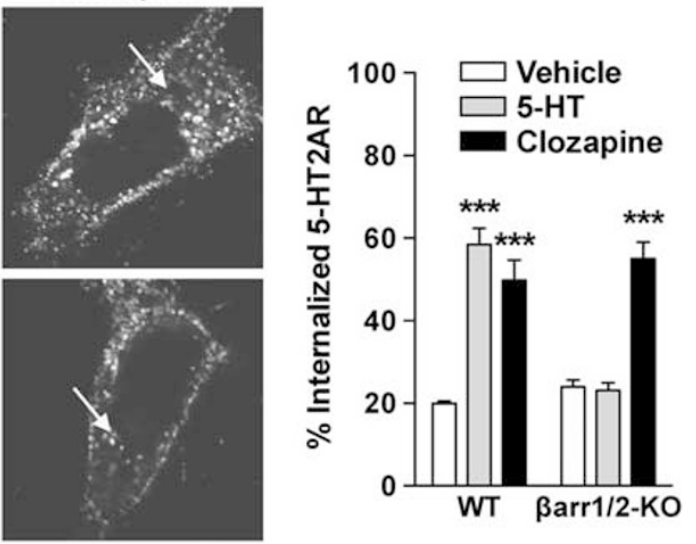

Figure I Clozapine antagonizes serotonin-induced 5-HT2AR: $\beta$ arrestin2 interactions. (a and b) The DiscoveRx PathHunter enzyme complementation assay was utilized to quantify $\beta$ arrestin2 interactions with the 5-HT2AR in U2OS cells. Mean \pm SEM are provided. (a) Serotonin (5-HT), but neither clozapine nor MI00907, induces robust interactions between Barrestin2 and the 5-HT2AR (two-way analysis of variance (ANOVA) for interaction of drug $x$ concentration: 5-HT vs clozapine, $\mathrm{F}_{(9,60)}=354.64$, $p<0.000 \mathrm{I}$; 5-HT vs MI00907, $\mathrm{F}_{(9,50)}=397.8 \mathrm{I}, \mathrm{p}<0.000 \mathrm{I} ; n=3-4$ independent experiments performed in triplicate). (b) 5-HT2AR U2OS DiscoveRx cells were pretreated with either clozapine or MI00907 for 60 min before stimulation with $500 \mathrm{nM}$ serotonin. Both MI00907 and clozapine fully block serotonin-induced $\beta$ arrestin2 interactions with the 5-HT2AR, although MI 00907 is more potent than clozapine (two-way ANOVA for interaction of drug $\times$ concentration: MI00907 vs clozapine, $F_{(11,156)}=78.27, p<0.0001$; $n=6-9$ independent experiments performed in triplicate). (c) Barrestin2 translocation to the 5-HT2AR was visualized by confocal microscopy of HEK-293 cells transiently transfected with HA-5-HT2AR and $\beta$ arr2-GFP. $\beta$ Arr2-GFP is localized throughout the cytosol in vehicle $(20 \mu M$ ascorbate, $0.1 \%$ DMSO)-treated cells. Serotonin induces robust recruitment of $\beta$ arr2-GFP to the plasma membrane (arrow). Clozapine on its own does not induce detectable $\beta$ arr2-GFP translocation. Pretreatment with clozapine for $10 \mathrm{~min}$ before the addition of serotonin abrogates $\beta$ arr2-GFP recruitment to the membrane. Representative images from three independent transfections are provided (I $\mu \mathrm{M}, 10 \mathrm{~min}$ ). (d) Confocal microscopy was utilized to visualize HA-5-HT2AR internalization in WT and $\beta$ arrl/2$\mathrm{KO}$ MEFs. Cells were serum starved for $2 \mathrm{~h}$ before live-cell staining of the receptor and drug treatment ( $10 \mu \mathrm{M}$ for $30 \mathrm{~min})$. The receptor is localized to the plasma membrane of both WT and $\beta$ arr I/2-KO MEFs treated with vehicle (20 $\mu$ M ascorbate, $0.1 \%$ DMSO). Serotonin induces HA-5-HT2AR internalization in WT MEFs (arrow), but not MEFs lacking $\beta$ arrestins. Clozapine induces noticeable internalization in both WT and $\beta$ arrl/2-KO MEFs (arrows). Representative images from three independent transfections are provided. (e) The percentage of the receptor internalized in MEFs is quantified. Serotonin induces significant internalization in WT MEFs alone, whereas clozapine induces significant internalization in both genotypes (Student's t-test: vehicle vs drug within each genotype, $* * * * * 0.001 ; n=9-10$ cells per condition from at least three independent transfections).

whether $\beta$ arrestins influence clozapine-induced 5-HT2AR internalization, MEFs lacking both $\beta$ arrestin1 and $\beta$ arrestin2 were used to monitor the 5-HT2AR tagged with HA. In the untreated state, following serum-starvation, the HA-5HT2AR is primarily localized to the plasma membrane of both WT and $\beta$ arr1/2-KO MEFs. Treatment of WT MEFs with either serotonin or clozapine for $30 \mathrm{~min}$ induces internalization of HA-5-HT2AR into cytosolic vesicles. However, although serotonin loses its ability to internalize the 5-HT2AR in the $\beta$ arr1/2-KO MEFs, clozapine still 
promotes receptor internalization (Figure 1d), a property it shares with the hallucinogenic $N$-methyltryptamines, and 2,5-dimethoxy-4-iodoamphetamine (Bohn and Schmid, 2010; Schmid et al, 2008). Quantification of the percent of internalized HA-5-HT2AR receptors observed in WT and $\beta$ arr1/2-KO MEF cells following drug treatment further supports these observations (Figure 1e). These findings are consistent with previous works which also demonstrated that clozapine is able to internalize the 5-HT2AR in the absence of $\beta$ arrestins (Bhatnagar et al, 2001).

When overexpressed in immortal cell lines, the clozapinebound 5-HT2AR does not induce interactions with $\beta$ arrestins nor does it require them to internalize the receptor; however, assays in immortalized cell lines may not capture the actual signaling mechanisms utilized in endogenous settings. In the frontal cortex of rodents, serotonin induces
Akt activation downstream of the 5-HT2AR in a $\beta$ arrestin2dependent manner. Therefore, we asked whether clozapineinduced Akt phosphorylation in primary cortical neuronal cultures also utilizes a $\beta$ arrestin2-dependent mechanism. Primary neurons isolated from the frontal cortex of WT and $\beta$ arr2-KO neonates were treated with serotonin, clozapine, and M100907. Both serotonin and clozapine activate Akt in WT neurons. However, unlike serotonin, clozapine also induces Akt phosphorylation in the absence of $\beta$ arrestin2. In this assay, M100907 acts as an antagonist at the receptor, in that it induces no Akt phosphorylation in neurons from either genotype (Figure 2a) and pretreatment with M100907 blocks serotonin and clozapine-induced Akt phosphorylation in WT cortical neurons (Figure 2b), and clozapineinduced Akt phosphorylation in the $\beta$ arr2-KO neurons (Figure 2c). These studies demonstrate that, although, both
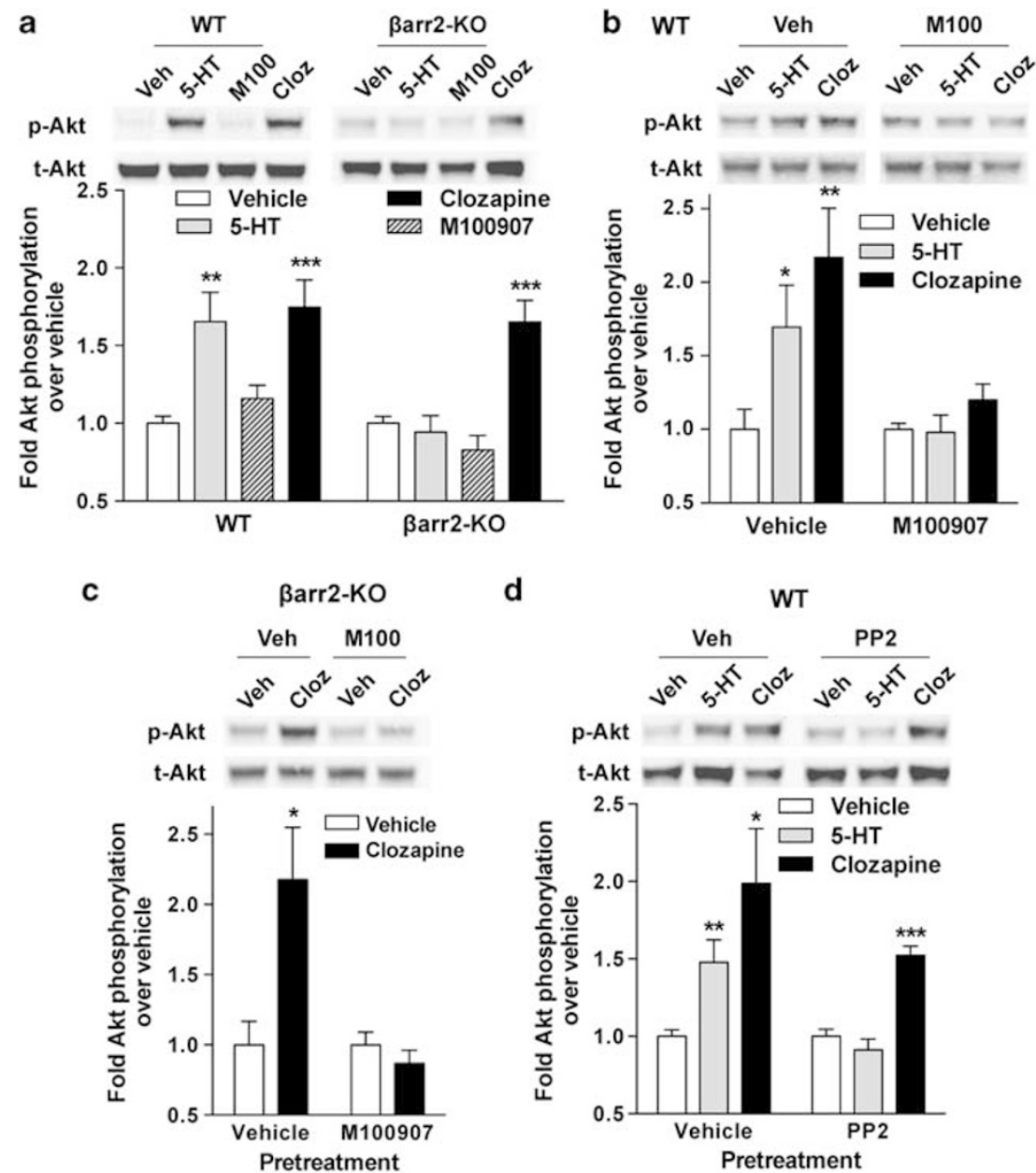

Figure 2 Clozapine induces 5-HT2AR-mediated Akt phosphorylation in a Barrestin2- and Src-independent manner. Primary neurons cultured from frontal cortices of WT and $\beta$ arr2-KO neonates were serum starved for I h before treatment with agonist (I $\mu$ M, in $20 \mu \mathrm{M}$ ascorbate) for I0 min. Lysates were prepared and Akt phosphorylation was determined by western blot analysis. Fold over vehicle was determined by normalizing phosphorylated Akt ( $\mathrm{p}$ Akt) to total Akt levels (t-Akt) and then normalizing to the average vehicle (Veh) levels within each experiment. Densitometric analysis (mean \pm SEM) and representative western blots are provided. (a) Serotonin $(5-H T)$ and clozapine induce Akt phosphorylation over vehicle levels in cortical neurons cultured from WT neonates, but only clozapine activates Akt in Barr2-KO neurons. MI00907 does not activate Akt in either genotype (Student's $t$ test: vehicle vs drug within each genotype, $* * * 0.01$, **** $p<0.001 ; n=12-18 \mathrm{WT}, 4-10 \beta$ arr2-KO, from at least three independent preparations of each genotype). (b and c) Pretreatment with the 5-HT2AR antagonist MI00907 (MI00, $100 \mathrm{nM}$ ) for 15 min blocks serotonin- and clozapine (Cloz)-induced Akt phosphorylation in WT (b) and Barr2-KO (c) neurons (Student's t-test: vehicle vs drug within the same pretreatment group, * $p<0.05$, *** $p<0.0$; $n=6-9$, from at least three independent preparations of each genotype). (d) Pretreatment with the Src inhibitor PP2 ( $\mu$ M, during the I h serum-starvation period) blocks serotonin-induced Akt phosphorylation, but does not block clozapine-induced Akt phosphorylation in WT neurons (Student's t-test: vehicle vs drug within the same pretreatment group, $* p<0.05$, $* * 0<0.01$, $* * * * 00.001 ; n=5-8$, from four independent preparations). 

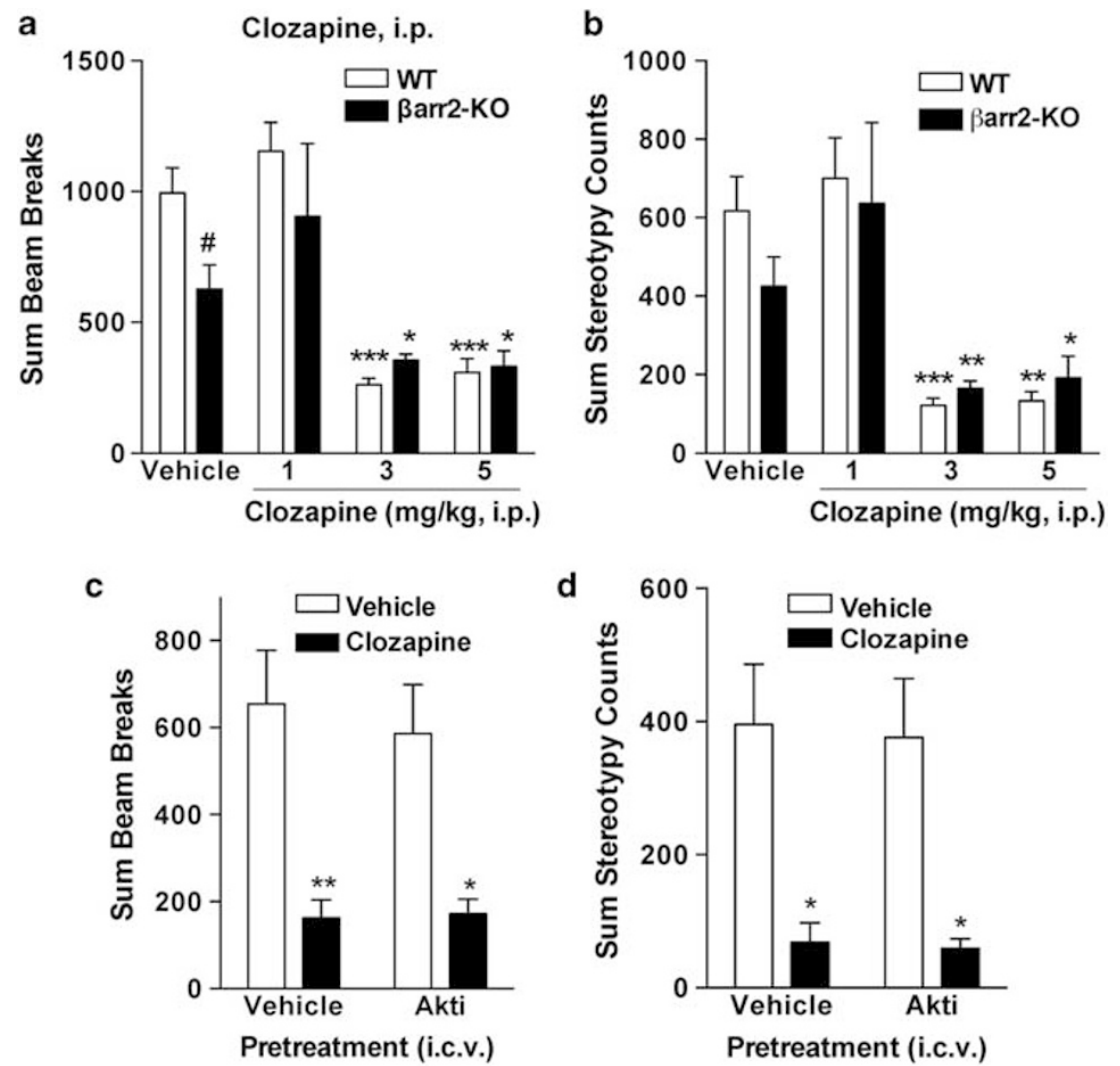

Figure 3 Clozapine-induced locomotor suppression occurs in the absence of $\beta$ arrestin2 and with inhibition of Akt. The locomotor activity of WT and Barr2-KO mice was monitored during a 30-min habituation period and for I h following treatment with vehicle (0.9\% saline) or clozapine (i.p.) (a and b). Both the 3 and $5 \mathrm{mg} / \mathrm{kg}$ doses of clozapine significantly inhibit both horizontal activity (a), sum beam breaks, and stereotypy (b), sum stereotypy counts, below vehicle levels (Student's $t$-test: vehicle vs dose within the same genotype, ${ }^{*} p<0.05,{ }^{*} * p<0.01$, WT vs $\beta$ arr $2-K O$ of the same dose, ${ }^{\#} p<0.05$; $n$ : vehicle $=7-9,1 \mathrm{mg} / \mathrm{kg}=4-5,3 \mathrm{mg} / \mathrm{kg}=5-8,5 \mathrm{mg} / \mathrm{kg}=4-8$ of each genotype). (c and d) Mice were pretreated with either vehicle ( $1 \%$ DMSO in dH ${ }_{2} \mathrm{O}$ ) or $100 \mathrm{ng}$ Akti (i.c.v.) for $30 \mathrm{~min}$ before clozapine administration. (c) Clozapine (vehicle + clozapine) decreases total beam breaks (c) and total stereotypy counts (d) observed in the 60 min following treatment compared with vehicle pretreated (vehicle + vehicle) animals. Akti by itself (Akti + vehicle) does not affect locomotion, nor does it modulate clozapine's ability (Akti + clozapine) to decrease horizontal activity (Student's t-test, vehicle vs drug within the same pretreatment group: $* p<0.05$, *** $p<0.01 ; n=5-6$ mice per treatment group).

serotonin and clozapine induce phosphorylation of the kinase through activation of the 5-HT2AR, the mechanisms by which they activate Akt diverge based on their necessity for $\beta$ arrestin2. Previously, we showed that $\beta$ arrestin2facilitated, serotonin-induced Akt phosphorylation is also dependent upon the tyrosine kinase Src (Schmid and Bohn, 2010). To determine whether the clozapine-bound receptor utilizes Src upstream of Akt, we pretreated WT neurons with the Src inhibitor PP2. Consistent with our previous findings, PP2 pretreatment inhibits serotonin's ability to activate Akt; however, clozapine's effects are not blocked by the Src inhibitor (Figure 2d).

Collectively, these data indicate that clozapine acts as an agonist at the 5-HT2AR to activate Akt in a manner that does not appear to utilize $\beta$ arrestin2. However, as the signaling in the neuronal cultures may not fully reflect what happens in the adult animal, we next determined whether $\beta$ arrestin 2 could influence the efficacy of clozapine in vivo. Using 5-HT2AR-KO mice, it has previously been demonstrated that the reduction in locomotion that is observed following acute administration of clozapine is mediated by 5-HT2AR expressed in the forebrain (McOmish et al, 2012).
To test whether clozapine's ability to decrease locomotion is also $\beta$ arrestin2 dependent, the locomotor activity of WT and $\beta$ arr2-KO mice was monitored following treatment with clozapine. Compared with vehicle-treated animals, both the 3 and $5 \mathrm{mg} / \mathrm{kg}$ doses of clozapine reduce both the horizontal activity and stereotypy of mice; however, no differences were observed in the degree of the reduction between the WT and $\beta$ arr2-KO mice (Figure 3a and b). We then tested whether the downstream activation of Akt is necessary for clozapine's inhibitory effects on locomotion using the Akt1/2 isozymeselective inhibitor VIII (Akti). For locomotor activity assays, WT mice were pretreated with either vehicle or $100 \mathrm{ng}$ Akti 30 min before clozapine administration. Pretreatment with Akti did not reduce the amount of locomotion observed in vehicle-treated animals, nor did it affect the reduction in locomotion observed following clozapine treatment (Figure $3 \mathrm{c}$ and $\mathrm{d}$ ). Collectively, these studies show that clozapine-induced decreases in basal locomotion are not dependent on $\beta$ arrestin 2 or the activation of Akt.

Antagonism of NMDA receptors by MK-801 or PCP induces hyperlocomotion in rodents; this response is often used to model psychosis and, importantly, antipsychotic 
drugs like clozapine also suppress this hyperactivity. To test whether clozapine's ability to inhibit NMDA receptormediated hyperlocomotion involved $\beta$ arrestin2 or Akt, we first evaluated WT and $\beta$ arr2-KO mice for their locomotor responses to either MK-801 or PCP alone. MK-801 by itself induces a similar increase in both horizontal beam breaks (Figure 4a) and stereotypy counts (Figure 4e), across multiple doses tested, in both WT and $\beta$ arr2-KO mice. Three different doses of PCP also induce comparable hyperactivity in both genotypes (Figure $4 \mathrm{i}$ and $\mathrm{m}$ ). Next, clozapine's ability to reduce MK-801- or PCP-induced hyperlocomotion was determined by pretreating the mice with clozapine $30 \mathrm{~min}$ before the NMDA receptor antagonist. We used a low dose of clozapine $(1 \mathrm{mg} / \mathrm{kg})$ as the a

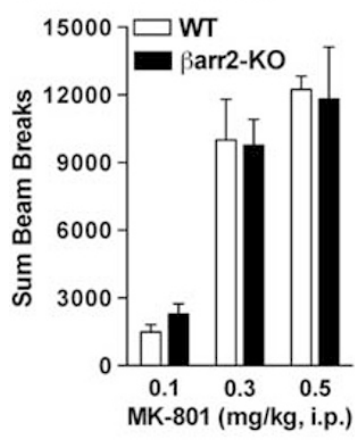

e

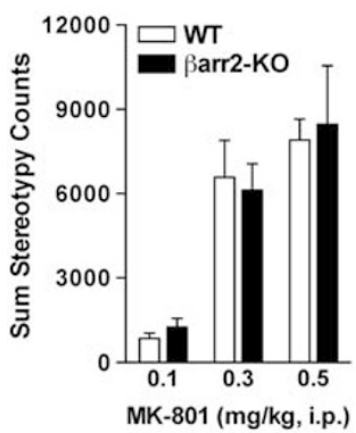

i

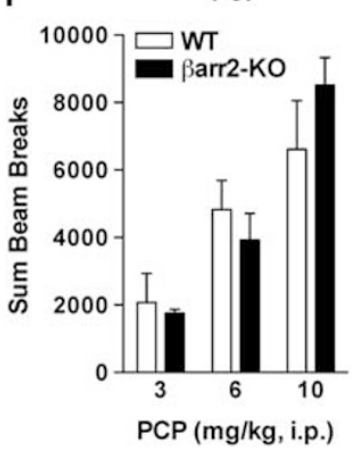

m

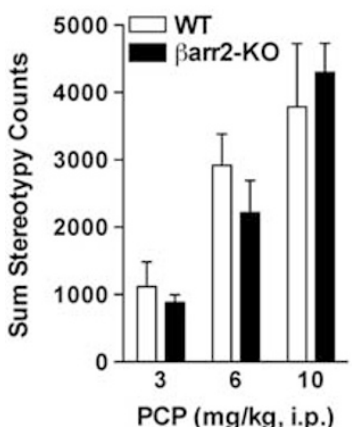

b

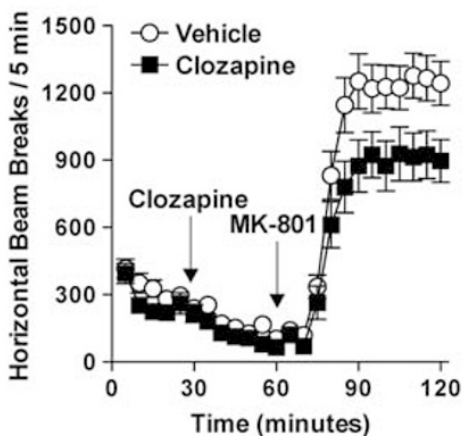

f
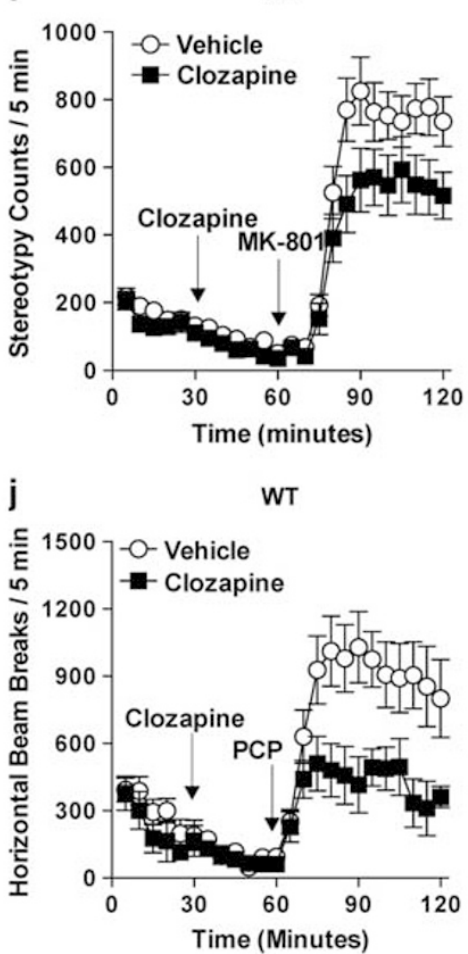

n

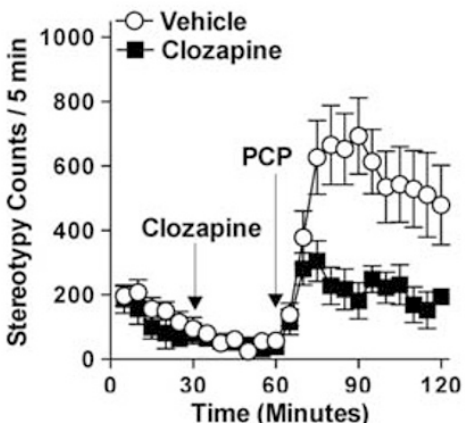

c

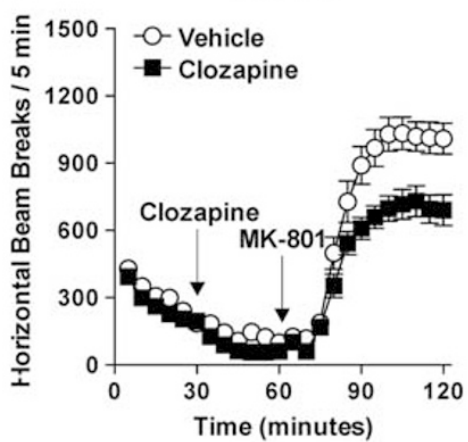

g

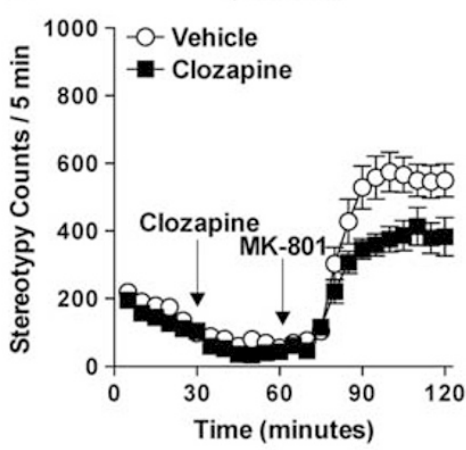

ßarr2-KO

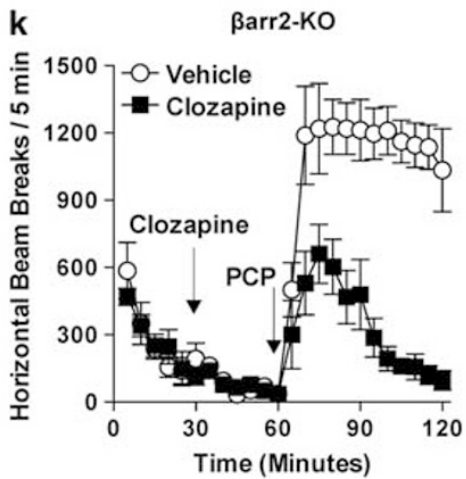

o

ßarr2-KO

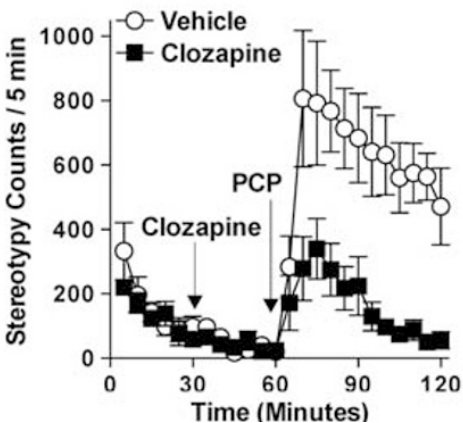

d

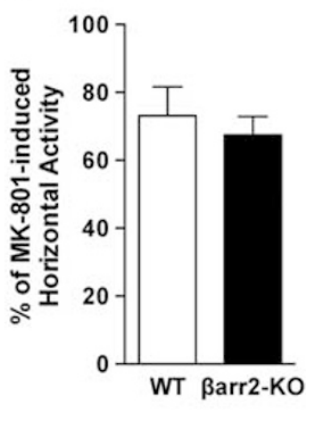

h

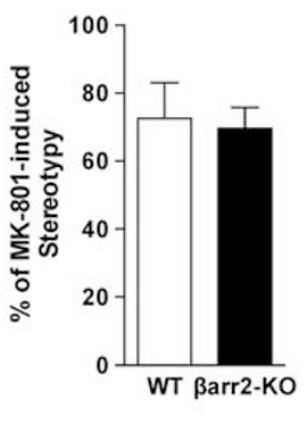

I

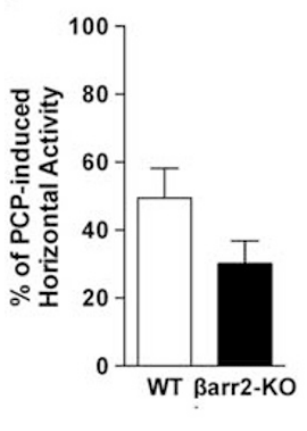

p

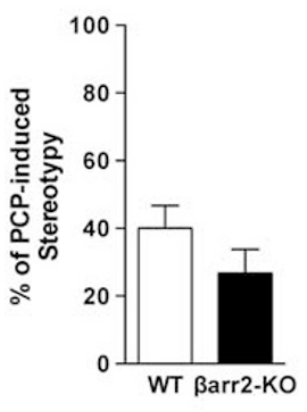


suppression of MK-801-induced hyperlocomotion at this dose has been shown to be 5-HT2AR-mediated (Fribourg et al, 2011). Clozapine decreases MK-801-induced horizontal locomotor activity and stereotypy in WT and $\beta$ arr2-KO mice to a similar extent (Figure $4 \mathrm{~b}, \mathrm{c}, \mathrm{f}$, and $\mathrm{g}$ ), indicating that clozapine retains efficacy in the absence of $\beta$ arrestin2. Similarly, a $30-\mathrm{min}$ pretreatment with clozapine is equally effective in reducing PCP-mediated hyperactivity in both genotypes (Figure 4j, k, n, and o). Analysis of the degree of inhibition in the two genotypes reveals that clozapine decreases the hyperlocomotion observed following treatment with either MK-801 or PCP to a similar extent, regardless of $\beta$ arrestin2 expression (Figure $4 \mathrm{~d}, \mathrm{~h}, \mathrm{l}$, and $\mathrm{p}$ ). Collectively, these findings suggest that clozapine remains effective in suppressing NMDA receptor antagonist-induced hyperactivity regardless of $\beta$ arrestin2.

Next, we sought to evaluate whether the downstream activation of Akt is critical for clozapine's inhibitory effects on MK-801 stimulated. WT mice were pretreated with either vehicle or $100 \mathrm{ng}$ Akti for $30 \mathrm{~min}$ before clozapine administration, which was $60 \mathrm{~min}$ before MK-801 treatment. Alone, Akti had no effect on MK-801-stimulated locomotion, as measured by horizontal beam breaks and stereotypy counts. However, inhibition of Akt attenuates clozapine's efficacy suggesting that the activation of Akt is required for clozapine to disrupt the hyperactivity induced in this mouse model of schizophrenia (Figure 5a-d). To demonstrate that Akt was inhibited under these conditions, a separate cohort of mice was treated as described for the activity assays and the frontal cortex was dissected. Similar to what was observed in the primary neuronal cultures, a 45-min treatment with clozapine (the time point when clozapine begins to inhibit MK-801-induced hyperlocomotion) induces Akt phosphorylation in the adult mouse frontal cortex. Pretreatment with $100 \mathrm{ng}$ Akti for $30 \mathrm{~min}$ before challenging with clozapine inhibits clozapine-mediated Akt phosphorylation (Figure 5e), suggesting the clozapineinduced activation of Akt has a significant role in mediating its physiological actions countering MK-801-induced hyperlocomotor activity.

\section{DISCUSSION}

Although clozapine and serotonin both act as agonists for inducing 5-HT2AR internalization and Akt phosphorylation, they differ in the manner through which they mediate these events; this difference appears to center upon the role of $\beta$ arrestin2. Serotonin induces the recruitment of $\beta$ arrestin2 to the 5-HT2AR and requires $\beta$ arrestins for the internalization of the receptor (Figure 1) as well as activating Akt in primary cortical neurons (Figure 2). In contrast, clozapine antagonizes $\beta$ arrestin2 interactions with the 5-HT2AR (Figure 1a-c), internalizes the receptor independent of $\beta$ arrestin expression (Figure 1d and e) and leads to Akt phosphorylation in neurons cultured from either WT or Barr2-KO mice (Figure 2). Moreover, the deletion of $\beta$ arrestin2 has no effect on clozapine's ability to suppress locomotion compared with vehicle-treated animals (Figure 3) nor does it impair clozapine's ability to decrease MK-801 or PCP-induced hyperactivity in mice (Figure 4). Inhibition of Akt significantly attenuates the suppression of MK-801stimulated locomotor activity by clozapine in WT mice (Figure 5), suggesting that the activation of this pathway may be critical for clozapine's antipsychotic effects.

Previously, we showed that serotonin-mediated activation of Akt is Barrestin2- and Src-dependent and that this signaling event is necessary for the serotonin-induced head twitch response in mice (Schmid and Bohn, 2010). Clozapine-mediated Akt phosphorylation is blocked by M100907, a selective and potent 5-HT2AR antagonist. However, clozapine's activation of Akt persists in the presence of Src inhibitors as well as in the absence of $\beta$ arrestin2. Interestingly, even though Akt is required for the serotonin-induced head twitch response, clozapine does not induce the head twitch in mice (data not shown), but functions as a serotonin antagonist in this mouse behavioral

Figure 4 Clozapine suppresses NMDA receptor antagonist-induced hyperlocomotion in both WT and $\beta$ arr2-KO mice. Locomotor activity was monitored for WT and $\beta$ arr2-KO mice during a 30-min habituation period, in some cases, a 30-min pretreatment with I mg/kg clozapine (i.p.) or vehicle (0.9\% saline) and for I h following treatment (i.p.) with either MK-80 I (a-h) or PCP (i-p). Mean \pm SEM are shown. (a) WT and $\beta$ arr2-KO mice do not differ in the sum of horizontal beam breaks observed following administration of three different doses of MK-80I (Student's $t$-test, $p>0.05 ; n: 0.1 \mathrm{mg} / \mathrm{kg}=4$, $0.3 \mathrm{mg} / \mathrm{kg}=12,0.5 \mathrm{mg} / \mathrm{kg}=6$ of each genotype). (b and c) Clozapine pretreatment decreases MK-80 I-induced ( $0.3 \mathrm{mg} / \mathrm{kg}$ ) horizontal beam breaks in WT (b) and $\beta$ arr2-KO (c) mice (two-way analysis of variance (ANOVA) for WT: for pretreatment, $F_{(1,480)}=43.28, p<0.0001$, for time, $F_{(11.480)}=34.67$, $p<0.000$ I; for $\beta$ arr2-KO: for pretreatment, $F_{(1,612)}=70.34, p<0.000 \mathrm{I}$, for time, $F_{(11,612)}=51.19, p<0.000$ I; $n=19-23 \mathrm{WT}$, 23-30 $\beta$ arr2-KO per treatment group). (d) Clozapine inhibits the level of horizontal activity observed in the I-h period following administration of MK-80 I (0.3 mg/kg) in both WT and $\beta$ arr2-KO mice to a similar extent. Total activity observed following clozapine treatment was normalized the average activity in mice that received vehicle and are shown as a percent (Student's t-test: $p>0.05)$. (e) There is also no difference between the genotypes in the sum of the stereotypy counts observed following administration of three different doses of MK-80I (Student's t-test, $p>0.05)$. ( $\mathrm{f}$ and $\mathrm{g}$ ) Clozapine pretreatment decreases MK-80Iinduced $(0.3 \mathrm{mg} / \mathrm{kg})$ stereotypy counts in both WT (f) and Barr2-KO (g) mice (two-way ANOVA for WT: for pretreatment $\mathrm{F}_{(\mathrm{I} .480)}=29.83$, $p<0.000 \mathrm{I}$, for time, $F_{(I 1,480)}=23.00, p<0.000$ I; for $\beta$ arr2-KO: for pretreatment $F_{(I .564)}=42.06, p<0.000$ I, for time, $F_{(I 1.564)}=27.85$, $p<0.000$ I). (h) Clozapine inhibits the sum stereotypy counts observed in the I-h period following administration of MK-80 I $(0.3 \mathrm{mg} / \mathrm{kg})$ in both WT and $\beta$ arr2-KO mice to a similar extent (Student's t-test: $p>0.05$ ). (i) $W T$ and $\beta$ arr2-KO mice do not differ in the sum of horizontal beam breaks observed following administration of three different doses of PCP (Student's t-test, $p>0.05 ; n: 3 \mathrm{mg} / \mathrm{kg}=4 ; 6 \mathrm{mg} / \mathrm{kg}=10,10 \mathrm{mg} / \mathrm{kg}=10$ of each genotype). (j and $\mathrm{k}$ ) Clozapine pretreatment decreases PCP-induced $\left(10 \mathrm{mg} / \mathrm{kg}\right.$ ) horizontal beam breaks in WT (j) and $\beta$ arr2-KO $(\mathrm{k})$ mice (two-way ANOVA for WT: for pretreatment, $\mathrm{F}_{(\mathrm{I}, 144)}=59.02, p<0.000 \mathrm{I}$, for time, $F_{(I I, 144)}=2.17, p=0.0191$; for $\beta$ arr2-KO: for pretreatment, $F_{(1,132)}=224.12, p<0.0001$, for time, $F_{(I I, 132)}=3.09$, $\left.p=0.0010\right)$. $(I)$ Clozapine inhibits the total level of horizontal activity observed following administration of PCP $(10 \mathrm{mg} / \mathrm{kg})$ in both WT and $\beta$ arr2-KO mice to a similar extent (Student's t-test: $p>0.05)$. (m) WT and $\beta$ arr2-KO mice do not differ in the total stereotypy counts observed following administration of three different doses of PCP (Student's t-test: $p>0.05$ ). ( $n$ and o) Clozapine pretreatment decreases PCP-induced ( $10 \mathrm{mg} / \mathrm{kg}$ ) stereotypy counts in both WT (n) and $\beta$ arr2$\mathrm{KO}$ (o) mice (two-way ANOVA for WT: for pretreatment $\mathrm{F}_{(1,144)}=65.43, p<0.000 \mathrm{I}$, for time, $\mathrm{F}_{(11,144)}=1.80$, $p=0.0594$; for $\beta$ arr2-KO: for pretreatment $F_{(1,132)}=101.08, p<0.0001$, for time, $\left.F_{(11,132)}=2.05, p=0.0288\right)$. (p) Clozapine inhibits the total levels of stereotypy counts observed following administration of PCP $(10 \mathrm{mg} / \mathrm{kg})$ in both WT and $\beta$ arr2-KO mice to a similar extent (Student's t-test: $p>0.05)$. 

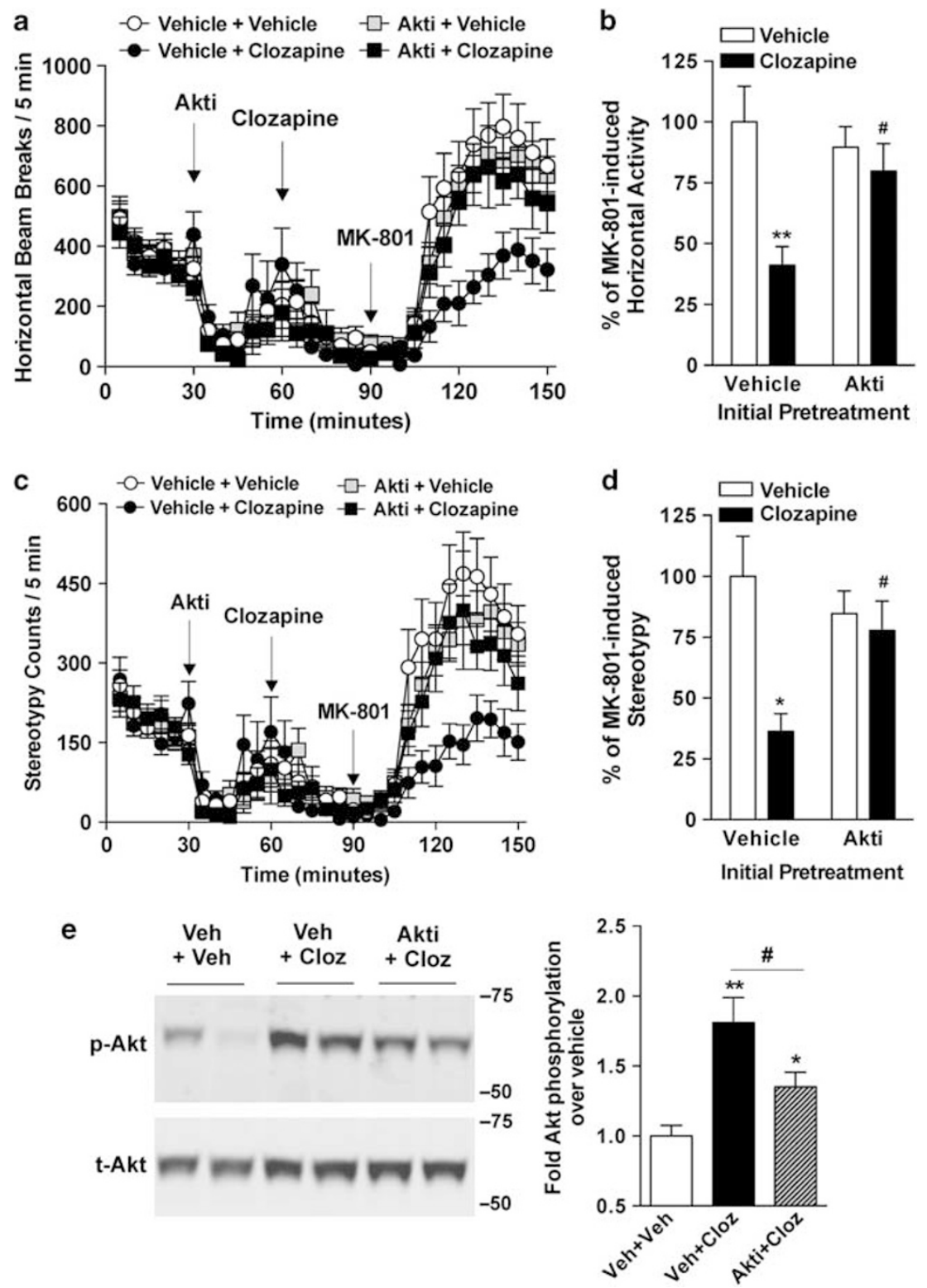

Figure 5 Akti-I/2 inhibits clozapine's ability to suppress MK-80I-induced hyperlocomotion in WT mice. (a-d) WT mice were habituated for 30 min, pretreated with either Akti- I/2 (Akti, I $00 \mathrm{ng}$, i.c.v.) or vehicle $\left(0.1 \% \mathrm{DMSO}\right.$ in $\mathrm{dH}_{2} \mathrm{O}$ ) for $30 \mathrm{~min}$, treated with either clozapine (I mg/kg, i.p.) or vehicle (0.9\% saline) and then challenged with MK-80I (0.3 mg/ $/ \mathrm{kg}$, i.p.). Locomotor activity was monitored and mean \pm SEM are shown ( $n=14$ vehicle + vehicle, 8 vehicle + clozapine, 9 Akti + vehicle, 8 Akti + clozapine). (a) Clozapine (vehicle + clozapine) decreases MK-80 I-induced horizontal beam breaks compared with vehicle pretreated mice (vehicle + vehicle; two-way analysis of variance (ANOVA) for pretreatment: $F_{(1,240)}=65.64, p<0.000 \mathrm{I}$; for time: $F_{(11.240)}=9.30, p<0.000 I$ ). Akti on its own (Akti + vehicle) does not decrease MK-80I-induced hyperactivity (two-way ANOVA for pretreatment: $F_{(1,252)}=2.22, p<0.1375$; for time: $F_{(11,252)}=17.06, p<0.0001$ ). Akti pretreatment (Akti + clozapine) blocks clozapine's ability to decrease MK-80 I-induced hyperactivity (vehicle + clozapine; two-way ANOVA for pretreatment: $F_{(I, 168)}=49.10, p<0.000 I$; for time: $F_{(I I, 168)}=12.72$, $p<0.000 I$ ). (b) Analysis of the sum beam breaks observed within each treatment group compared with mice, which received MK-80I alone (vehicle + vehicle) shows that Akti attenuates clozapine's ability to inhibit hyperlocomotion (Student's t-test, vehicle + vehicle vs vehicle + clozapine, $* *$ $p<0.0$ l; vehicle + clozapine vs Akti + clozapine, ${ }^{\#} p<0.05$ ). (c) Analysis of the counts observed demonstrates that Akti inhibits clozapine's ability to block MK-80 I-induced stereotypy (two-way ANOVA vehicle + clozapine vs vehicle + vehicle, for pretreatment: $F_{(1,240)}=61.97, p<0.000$ I, for time: $F_{(11,240)}=7.39$, $p<0.000$ I; Akti + vehicle vs vehicle + vehicle, for pretreatment: $F_{(1,252)}=3.71, p=0.0551$, for time: $F_{(11.252)}=13.30, p<0.0001$; Akti + clozapine vs vehicle + clozapine, for pretreatment: $F_{(1,168)}=46.98$, $p<0.000$ I, for time: $\left.F_{(11,168)}=9.64, p<0.000 I\right)$. (d) Analysis of the total stereotypy counts observed within each treatment group, compared with mice, which received MK-80I alone (vehicle + vehicle), shows that Akti attenuates clozapine's ability to inhibit hyperlocomotion (Student's t-test, vehicle + vehicle vs vehicle + clozapine, ${ }^{*} p<0.05$; vehicle + clozapine vs Akti + clozapine, $\left.{ }^{\#} p<0.05\right)$. (e) WT mice were pretreated with Akti (I 00 ng, i.c.v.) or vehicle (0I.\% DMSO in $\mathrm{dH}_{2} \mathrm{O}$ ) for $30 \mathrm{~min}$ and then treated with either clozapine (I mg/kg, i.p.) or vehicle $(0.9 \%$ saline). Forty-five minutes later frontal cortex was isolated, lysates were prepared, and Akt phosphorylation levels were determined by western blot analysis. Mean \pm SEM are shown. Pretreatment with Akti significantly decreases clozapine-mediated Akt phosphorylation in the mouse frontal cortex (Student's t-test: vehicle + vehicle vs drug challenge, $* p<0.05$, ${ }_{*}^{*} p<0.0$ I; vehicle + clozapine vs Akti + clozapine, ${ }^{\#} p<0.05 ; n=8-1$ I for each treatment group). 
model (Tang et al, 1997). Moreover, hallucinogenic $\mathrm{N}$-methyltryptamines do not activate Akt downstream of 5-HT2AR in cortex, or in cortical neurons, yet these agonists induce a robust head twitch response in mice. Together, these studies demonstrate that activation of Akt downstream of the 5-HT2AR is not sufficient for the induction of a head twitch response. In addition, they suggest that the functional outcome of 5-HT2AR-mediated Akt phosphorylation differs depending on which ligand is acting at the receptor, although further studies are necessary to delineate whether these differences are due to the activation of different pools of Akt, different populations of 5-HT2AR within the same neuron, or different neurons altogether.

The studies presented here suggest that clozapine's efficacy to suppress MK-801-induced hyperactivity are dependent upon Akt activation and imply that this may have some bearing on its antipsychotic efficacy. Although clozapine induces Akt phosphorylation in mouse cortex and primary cortical neurons, the 5-HT2AR antagonist, M100907, does not. However, M100907, is still able to suppress MK-801-induced hyperlocomotion in rodents (Higgins et al, 2003; Meltzer and Massey, 2011), suggesting that the effects of clozapine are mediated by a different mechanism than that utilized by M100907, a mechanism that extends beyond the shared property of the two compounds being antagonists at 5-HT2AR.

The inhibition of Akt appears to be integrally important in the clozapine's efficacy in suppressing MK-801-induced hyperactivity; however, it does not impair clozapine's ability to suppress basal activity, suggesting that the general sedative effects of clozapine may be due to a different mechanism. These effects of clozapine, a drug that has a highly nonselective receptor-binding profile, may be mediated by actions at other receptors. Although clozapine-induced suppression of basal activity has shown to be 5-HT2AR dependent, low doses of clozapine (below $3 \mathrm{mg} / \mathrm{kg}$ ) do not significantly decrease locomotion in mice (McOmish et al, 2012). In contrast, its ability to prevent the MK-801-induced hyperactive state is completely absent in the 5-HT2AR-KO mice when low doses of clozapine (up to $1.5 \mathrm{mg} / \mathrm{kg}$ ) are used (Fribourg et al, 2011). At higher doses, however, clozapine is able to suppress MK-801-induced hyperactivity in the 5-HT2AR-KO mouse, implicating other receptors in modulating this response (Fribourg et al, 2011).

Many antipsychotic drugs, including clozapine, also antagonize interactions between $\beta$ arrestin2 and the D2 DA receptor (Masri et al, 2008). Interestingly, the activation of the D2 DA receptors leads to the subsequent inhibition of Akt in striatum by inducing the formation of a signaling complex with the receptor, $\beta$ arrestin2, Akt, and protein phosphatase 2A (PP2A), which in turn facilitates the dephosphorylation of Akt by PP2A (Beaulieu et al, 2005, 2004, 2007). Antipsychotics are believed to interfere with the formation of the $\beta$ arrestin2-D2 receptor complex, thereby preventing Akt dephosphorylation (Masri et al, 2008). Although the mechanism by which clozapine induces the phosphorylation of Akt downstream of the 5-HT2AR remains to be determined, it is attractive to speculate that it may similarly be blocking the dephosphorylation of the kinase rather than inducing its phosphorylation. Alternatively, the 5-HT2AR has been shown to dimerize with both the DA D2 receptor and the metabotropic glutamate
mGluR2 receptor (Fribourg et al, 2011; Lukasiewicz et al, 2010). In Xenopus oocytes, clozapine has been shown to act at the 5-HT2AR/mGluR2 complex and block serotoninmediated $\mathrm{G} \alpha_{\mathrm{q}}$ signaling while enhancing glutamatemediated $\mathrm{G} \alpha_{\mathrm{i}}$ signaling (Fribourg et al, 2011). Although clozapine antagonizes direct $G$ protein coupling to the 5-HT2AR, it is possible that clozapine could promote Akt phosphorylation though a dimer-mediated signaling event.

Collectively, these studies further implicate the Akt signaling cascade in the etiology of schizophrenia. Akt protein levels in the brains of individuals with schizophrenia have been reported to be lower than normal, whereas haloperidol-treated patients were reported to have increased kinase phosphorylation (Emamian et al, 2004). Similarly, an association with single-nucleotide polymorphisms of the AKT1 gene has been reported in Japanese schizophrenic patients (Ikeda et al, 2004). Our finding that Akt activation is necessary for clozapine-mediated inhibition of MK-801 hyperactivity in mice lends further support to the relationship between Akt signaling and psychosis. However, M100907, which we show herein does not lead to Akt activation, and SR43469B, another highly selective 5-HT2AR inverse agonist, have been found to be more effective than placebo in ameliorating psychotic symptoms in acutely psychotic patients with schizophrenia (S.G. Potkin, personal communication to H. Meltzer; Meltzer et al, 2004). Therefore, the question remains as to whether it will be of greater benefit for the treatment of schizophrenia to target a multi-functional kinase such as Akt or receptor-mediated signaling cascades. The further elucidation of such signaling mechanisms in vivo could provide insights into the development of better pharmacotherapeutics for the treatment of neuropsychiatric disorders.

\section{FUNDING AND DISCLOSURE}

This work was funded by a grant awarded to Dr Laura Bohn from NIH/ National Institutes on Drug Abuse (R01DA025158) and the Scripps-Vanderbilt Human Chemical Sciences Institute (in collaboration with Dr Meltzer). In the last 3 years, Dr Bohn has consulted for and received compensation from Trevena, Purdue Pharma LP, Mencuro Therapeutics, and Eli Lilly. In the last 3 years, Dr Meltzer has consulted for, or received grant funding, or both, and received compensation from ACADIA, Alkermes, DaiNippon Sumitomo, EnVivo, Lundbeck, Merck, Teva, and Sunovion. Dr Meltzer has also received funding from the Weisman Family Foundation. The remaining authors declare no conflict of interest.

\section{ACKNOWLEDGEMENTS}

The original $\beta$ arrestin2-KO mouse colony was provided by Dr Robert J Lefkowitz, MD, Duke University, HHMI, and has been maintained by the Bohn laboratory for 10 years.

\section{REFERENCES}

Beaulieu JM, Sotnikova TD, Marion S, Lefkowitz RJ, Gainetdinov RR, Caron MG (2005). An Akt/beta-arrestin 2/PP2A signaling complex 
mediates dopaminergic neurotransmission and behavior. Cell 122: 261-273.

Beaulieu JM, Sotnikova TD, Yao WD, Kockeritz L, Woodgett JR, Gainetdinov RR et al (2004). Lithium antagonizes dopaminedependent behaviors mediated by an AKT/glycogen synthase kinase 3 signaling cascade. Proc Natl Acad Sci USA 101: 5099-5104.

Beaulieu JM, Tirotta E, Sotnikova TD, Masri B, Salahpour A, Gainetdinov RR et al (2007). Regulation of Akt signaling by D2 and D3 dopamine receptors in vivo. J Neurosci 27: 881-885.

Bhatnagar A, Willins DL, Gray JA, Woods J, Benovic JL, Roth BL (2001). The dynamin-dependent, arrestin-independent internalization of 5-hydroxytryptamine 2A (5-HT2A) serotonin receptors reveals differential sorting of arrestins and 5-HT2A receptors during endocytosis. J Biol Chem 276: 8269-8277.

Bohn LM, Schmid CL (2010). Serotonin receptor signaling and regulation via beta-arrestins. Crit Rev Biochem Mol Biol 45: 555-566.

Corne SJ, Pickering RW (1967). A possible correlation between drug-induced hallucinations in man and a behavioural response in mice. Psychopharmacologia 11: 65-78.

Dwyer DS, Donohoe D (2003). Induction of hyperglycemia in mice with atypical antipsychotic drugs that inhibit glucose uptake. Pharmacol Biochem Behav 75: 255-260.

Emamian ES, Hall D, Birnbaum MJ, Karayiorgou M, Gogos JA (2004). Convergent evidence for impaired AKT1-GSK3beta signaling in schizophrenia. Nat Genet 36: 131-137.

Fribourg M, Moreno JL, Holloway T, Provasi D, Baki L, Mahajan R et al (2011). Decoding the signaling of a GPCR heteromeric complex reveals a unifying mechanism of action of antipsychotic drugs. Cell 147: 1011-1023.

Gainetdinov RR, Mohn AR, Caron MG (2001). Genetic animal models: focus on schizophrenia. Trends Neurosci 24: 527-533.

Gleason SD, Shannon HE (1997). Blockade of phencyclidineinduced hyperlocomotion by olanzapine, clozapine and serotonin receptor subtype selective antagonists in mice. Psychopharmacology 129: 79-84.

Gonzalez-Maeso J, Weisstaub NV, Zhou M, Chan P, Ivic L, Ang R et al (2007). Hallucinogens recruit specific cortical 5-HT(2A) receptor-mediated signaling pathways to affect behavior. Neuron 53: 439-452.

Higgins GA, Enderlin M, Haman M, Fletcher PJ (2003). The 5-HT2A receptor antagonist M100,907 attenuates motor and 'impulsive-type' behaviours produced by NMDA receptor antagonism. Psychopharmacology 170: 309-319.

Ikeda M, Iwata N, Suzuki T, Kitajima T, Yamanouchi Y, Kinoshita Y et al (2004). Association of AKT1 with schizophrenia confirmed in a Japanese population. Biological psychiatry 56: 698-700.

Jones CA, Watson DJ, Fone KC (2011). Animal models of schizophrenia. Br J Pharmacol 164: 1162-1194.

Lu XH, Bradley RJ, Dwyer DS (2004). Olanzapine produces trophic effects in vitro and stimulates phosphorylation of $\mathrm{Akt} / \mathrm{PKB}$, ERK1/2, and the mitogen-activated protein kinase $\mathrm{p} 38$. Brain Res 1011: 58-68.

Lukasiewicz S, Polit A, Kedracka-Krok S, Wedzony K, Mackowiak M, Dziedzicka-Wasylewska M (2010). Hetero-dimerization of serotonin 5-HT(2A) and dopamine $\mathrm{D}(2)$ receptors. Biochim Biophys Acta 1803: 1347-1358.

Masri B, Salahpour A, Didriksen M, Ghisi V, Beaulieu JM, Gainetdinov RR et al (2008). Antagonism of dopamine D2 receptor/beta-arrestin 2 interaction is a common property of clinically effective antipsychotics. Proc Natl Acad Sci USA 105: 13656-13661.

Matsubara S, Meltzer HY (1989). Effect of typical and atypical antipsychotic drugs on 5-HT2 receptor density in rat cerebral cortex. Life Sci 45: 1397-1406.

McOmish CE, Lira A, Hanks JB, Gingrich JA (2012). Clozapineinduced locomotor suppression is mediated by $5-\mathrm{HT}(2 \mathrm{~A})$ receptors in the forebrain. Neuropsychopharmacology 37: 2747-2755.

Meltzer HY (2012). Clozapine: balancing safety with superior antipsychotic efficacy. Clin Schizophr Relat Psychoses 6: 134-144.

Meltzer HY (2013). Update on typical and atypical antipsychotic drugs. Annu Rev Med 64: 393-406.

Meltzer HY, Arvanitis L, Bauer D, Rein W (2004). Placebocontrolled evaluation of four novel compounds for the treatment of schizophrenia and schizoaffective disorder. Am J Psychiatry 161: 975-984.

Meltzer HY, Huang M (2008). In vivo actions of atypical antipsychotic drug on serotonergic and dopaminergic systems. Prog Brain Res 172: 177-197.

Meltzer HY, Massey BW (2011). The role of serotonin receptors in the action of atypical antipsychotic drugs. Curr Opin Pharmacol 11: 59-67.

Millan MJ, Brocco M, Gobert A, Joly F, Bervoets K, Rivet J et al (1999). Contrasting mechanisms of action and sensitivity to antipsychotics of phencyclidine versus amphetamine: importance of nucleus accumbens 5-HT2A sites for PCP-induced locomotion in the rat. Eur J Neurosci 11: 4419-4432.

Moreno JL, Holloway T, Umali A, Rayannavar V, Sealfon SC, Gonzalez-Maeso J (2013). Persistent effects of chronic clozapine on the cellular and behavioral responses to LSD in mice. Psychopharmacology 225: 217-226.

Peroutka SJ, Snyder SH (1980). Long-term antidepressant treatment decreases spiroperidol-labeled serotonin receptor binding. Science 210: 88-90.

Rajagopal S, Rajagopal K, Lefkowitz RJ (2010). Teaching old receptors new tricks: biasing seven-transmembrane receptors. Nat Rev Drug Discov 9: 373-386.

Raote I, Bhattacharyya S, Panicker MM (2013). Functional selectivity in serotonin receptor 2A (5-HT2A) endocytosis, recycling, and phosphorylation. Mol Pharmacol 83: 42-50.

Roth BL, Sheffler DJ, Kroeze WK (2004). Magic shotguns versus magic bullets: selectively non-selective drugs for mood disorders and schizophrenia. Nat Rev Drug Discov 3: 353-359.

Schmid CL, Bohn LM (2010). Serotonin, but not N-methyltryptamines, activates the serotonin $2 \mathrm{~A}$ receptor via a ss-arrestin2/Src/ Akt signaling complex in vivo. J Neurosci 30: 13513-13524.

Schmid CL, Raehal KM, Bohn LM (2008). Agonist-directed signaling of the serotonin $2 \mathrm{~A}$ receptor depends on beta-arrestin-2 interactions in vivo. Proc Natl Acad Sci USA 105: 1079-1084.

Sutton LP, Rushlow WJ (2011). The effects of neuropsychiatric drugs on glycogen synthase kinase-3 signaling. Neuroscience 199: 116-124.

Tang AH, Franklin SR, Himes CS, Smith MW, Tenbrink RE (1997). PNU-96415E, a potential antipsychotic agent with clozapine-like pharmacological properties. J Pharmacol Exp Ther 281: 440-447.

Urban JD, Clarke WP, von Zastrow M, Nichols DE, Kobilka B, Weinstein $\mathrm{H}$ et al (2007). Functional selectivity and classical concepts of quantitative pharmacology. J Pharmacol Exp Ther 320: $1-13$.

Weeks KR, Dwyer DS, Aamodt EJ (2011). Clozapine and lithium require Caenorhabditis elegans beta-arrestin and serum- and glucocorticoid-inducible kinase to affect Daf-16 (FOXO) localization. J Neurosci Res 89: 1658-1665.

Weiner DM, Burstein ES, Nash N, Croston GE, Currier EA, Vanover KE et al (2001). 5-hydroxytryptamine2A receptor inverse agonists as antipsychotics. J Pharmacol Exp Ther 299: 268-276.

Williams AA, Ingram WM, Levine S, Resnik J, Kamel CM, Lish JR et al (2012). Reduced levels of serotonin 2A receptors underlie resistance of Egr3-deficient mice to locomotor suppression by clozapine. Neuropsychopharmacology 37: 2285-2298.

Willins DL, Alsayegh L, Berry SA, Backstrom JR, Sanders-Bush E, Friedman L et al (1998). Serotonergic antagonist effects on trafficking of serotonin 5-HT2A receptors in vitro and in vivo. Ann N Y Acad Sci 861: 121-127. 
Willins DL, Berry SA, Alsayegh L, Backstrom JR, Sanders-Bush E, Friedman L et al (1999). Clozapine and other 5-hydroxytryptamine-2A receptor antagonists alter the subcellular distribution of 5-hydroxytryptamine-2A receptors in vitro and in vivo. Neuroscience 91: 599-606.

Xi D, Li YC, Snyder MA, Gao RY, Adelman AE, Zhang W et al (2011). Group II metabotropic glutamate receptor agonist ameliorates MK801-induced dysfunction of NMDA receptors via the Akt/GSK-3beta pathway in adult rat prefrontal cortex. Neuropsychopharmacology 36: 1260-1274.

Yadav PN, Kroeze WK, Farrell MS, Roth BL (2011). Antagonist functional selectivity: 5-HT2A serotonin receptor antagonists differentially regulate 5-HT2A receptor protein level in vivo. J Pharmacol Exp Ther 339: 99-105. 